\title{
Spatio-Temporal Clustering Hotspot di Sumatera Selatan Tahun 2002-2003 Menggunakan Algoritme ST-DBSCAN dan Bahasa Pemrograman R
}

\author{
Spatio-Temporal Clustering Hotspot in South Sumatera From 2002-2003 \\ Using ST-DBSCAN Algorithm and R Programming Language
}

\author{
NADINA ADELIA INDRAWAN, HARI AGUNG ADRIANTO*
}

\begin{abstract}
Abstrak
Kebakaran hutan merupakan permasalahan yang cukup serius di Indonesia. Salah satu indikator kemungkinan terjadinya kebakaran hutan dapat diketahui dengan kemunculan hotspot. Dataset hotspot merupakan data spasial yang berukuran besar karena dicatat setiap waktu. Spatial temporal-Density based clustering algorithm(ST-DBSCAN) merupakan salah satu algoritme yang mampu mengolah data spasial dan temporal. Penelitian ini mengimplementasikan algoritme ST-DBSCAN menggunakan bahasa pemrograman R. R adalah perangkat lunak komputasi statistik dan grafis. Bahasa $\mathrm{R}$ digunakan di kalangan ahli statistik dan data mining untuk mengembangkan perangkat lunak statistik dan analisis data. Clustering dilakukan terhadap dataset hotspot di Sumatera Selatan pada periode tahun 2002-2003. Dengan menggunakan parameter jarak spasial $\left(\right.$ Eps $_{1}$ $=0.2$ ), parameter jarak temporal $\left(\mathrm{Eps}_{2}=7\right)$ dan minimum anggota cluster (MinPts $=7$ ) didapatkan hasil 41 cluster dengan 712 noise.
\end{abstract}

Kata Kunci: kebakaran hutan, R, spatio-temporal, ST-DBSCAN, titik panas.

\begin{abstract}
Forest fire is a serious problem in Indonesia. One indicator of forest fires possibility can be seen through the appearance of hotspots. Hotspot dataset is large spatial data because its recorded each time. ST-DBSCAN is one of the algorithm which has the capability to process spatial and temporal data. This study is implementing Spatial temporal-Density based clustering algorithm(ST-DBSCAN) with $R$ language programming. $R$ is software environment for statistical computing and graphics. The $R$ language is widely used among statisticians and data miners for developing statistical software. Clustering is performed on hotspots dataset in South Sumatra in the period 2002-2003. By using the spatial distance parameter $($ Epsl $=0.2)$, the temporal distance parameters $($ Eps2 =7) and a minimum cluster members (MinPts $=7)$ showed 41 clusters with 712 noise.
\end{abstract}

Keywords: forest fire, hotspot, R, spatio-temporal, ST-DBSCAN.

\section{PENDAHULUAN}

Kebakaran hutan di Indonesia merupakan masalah yang terus berulang dan termasuk permasalahan yang serius. Menurut Adinugroho (2005) salah satu indikator kemungkinan terjadinya kebakaran hutan ialah hotspot. Dalam hal ini terdapat kemungkinan bahwa persebaran titik api menggerombol dalam ruang secara alami tidak tersebar acak sehingga data tersebut dapat dianalisis menggunakan teknik clustering.

Ada beberapa macam teknik clustering diantaranya k-means, hierachical cluster, DBSCAN dan ST-DBSCAN. Di antara semua metode clustering, algoritme DBSCAN merupakan salah satu metode yang paling baik untuk menemukan cluster dari database spasial yang besar (Gaonkar \& Sawant, 2013). ST-DBSCAN merupakan perluasan algoritme

Departemen Ilmu Komputer, Fakultas Matematika dan Ilmu Pengetahuan Alam, Institut Pertanian Bogor, Bogor 16680 *Penulis Korespondensi: Tel/Faks: 0251-8625584; Surel: agung@ipb.ac.id 
DBSCAN, jika DBSCAN hanya mengolah data spatial maka ST-DBSCAN mampu mengolah data temporal dengan menggunakan nilai Eps $_{1}$ (parameter jarak pada aspek spasial) dan nilai $\mathrm{Eps}_{2}$ (parameter jarak pada aspek temporal). ST-DBSCAN memiliki kelebihan lebih fleksibel dengan ukuran data yang besar karena merupakan teknik clustering yang berbasis kepadatan (Birant \& Kut, 2007).

$\mathrm{R}$ adalah perangkat lunak komputasi statistik dan grafis. $\mathrm{R}$ sangat efektif dalam hal memvisualisasikan cluster dan dalam pengelolaan data serta fasilitas penyimpanan. Selain itu $\mathrm{R}$ dapat dikembangkan sesuai kebutuhan dengan menambah fitur-fitur tambahan dalam bentuk paket ke dalam software R yang bersifat open source (Venables \& Smith, 2009).

Pada penelitian diimplementasikan algoritme ST-DBSCAN menggunakan bahasa pemrograman R. Data yang dipakai ialah dataset hotspot di Sumatera Selatan tahun 20022003. Diharapkan implementasi ST-DBSCAN dapat menghasilkan pola penyebaran hotspot sehingga kebakaran hutan di Indonesia dapat dikendalikan.

\section{METODE}

\section{Data Penelitian}

Wilayah penelitian melingkupi Provinsi Sumatera Selatan yang terletak antara $5^{\circ} 10^{\prime}$ sampa $1^{\circ} 20^{\prime}$ Lintang Selatan dan $101^{\circ} 40^{\prime}$ sampai 106 $30^{\circ}$ Bujur Timur (Gambar 3). Penelitian ini mengunakan dataset hotspot tahun 2002-2003 dengan $1^{\circ}$ mewakili jarak sekitar $110 \mathrm{~km}$.

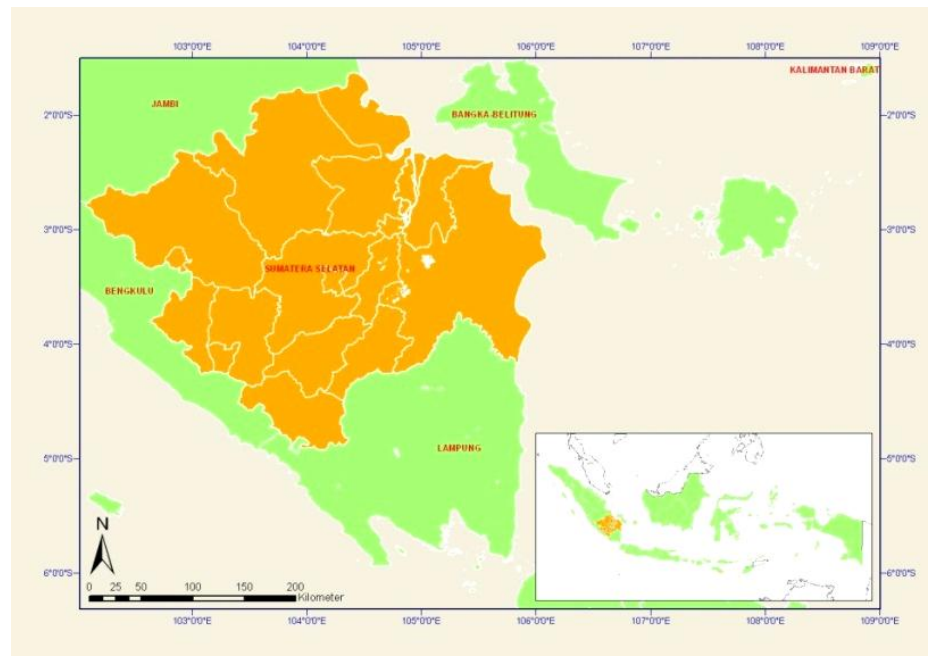

Gambar 1 Peta Provinsi Sumatera Selatan (Purwanto, 2012)

Data penelitian diperoleh dari Fire Information For Resource Management System (FIRMS) yang merupakan data hotspot MODIS yang disediakan oleh National Aeronautics and Space Administration (NASA). Variabel yang terdapat pada dataset meliputi titik spasial (latitude dan longitude), tingkat kecerahan pada piksel hotspot (Kelvin), ukuran piksel sebenarnya (scan dan track), tanggal dan waktu pengambilan data, satelit (Aqua dan Terra), confidence yang menunjukkan ukuran kualitas piksel pada setiap hotspot (skala 0-100 \%), versi pengambilan data (collection - angka sebelum desimal dan source - angka sesudah desimal yang mengindikasikan sumber data), dan FRP (menunjukkan piksel yang terintegrasi radiasi api dalam satuan MegaWatts). 


\section{Tahapan Penelitian}

Tahapan penelitian yang dilakukan pada penelitian ini ditunjukkan pada Gambar 4.

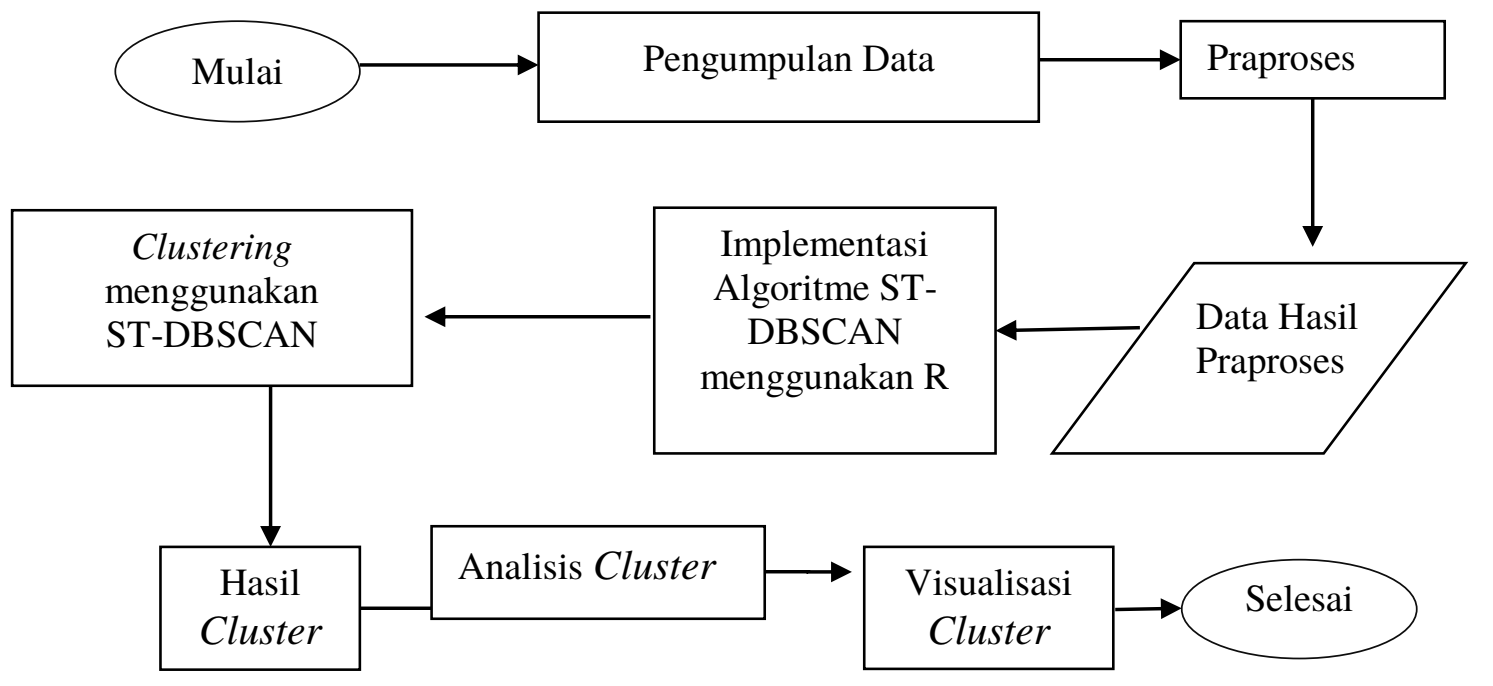

Gambar 2 Diagram alir penelitian

\section{Praproses Data}

Tahap praproses data terdiri atas tahapan transformasi data dan reduksi data. Pada tahap transformasi dilakukan perubahan tipe format data dengan merubah tipe format date menjadi tipe format number. Selain itu dilakukan tahapan reduksi data dengan melakukan pengurangan data dari 11 variabel menjadi 3 variabel yaitu longitude, latitude dan tanggal pemantauan hotspot.

\section{Clustering Menggunakan ST-DBSCAN}

Algoritme ST-DBSCAN merupakan pengembangan dari algoritme DBSCAN. Algoritme ST-DBSCAN membutuhkan empat parameter, yaitu Eps ${ }_{1}$ (parameter yang menyatakan jarak antar 2 objek di permukaan bumi), Eps 2 (parameter yang menyatakan jarak antar kejadian waktu), MinPts (jumlah anggota suatu cluster), dan $\Delta \in$ (Brian \& Kut, 2007). Pada penelitian ini hanya tiga parameter yang digunakan yaitu Eps 1 , Eps 2 dan MinPts.

Penentuan nilai parameter merujuk pada penelitian Purwanto (2012). Penentuan nilai ketiga paramater tersebut dilakukan agar mendapatkan total cluster dan noise dalam jumlah yang sedikit.

\section{Implementasi Algoritme ST-DBSCAN Menggunakan R}

Pada tahapan ini dilakukan modifikasi fungsi dbscan yang terdapat pada package fpc. Fungsi dbscan pada package fpc hanya menggunakan satu epsilon kemudian dimodifikasi menjadi st-dbscan dengan dua epsilon. Alur algoritme DBSCAN dan ST-DBSCAN dapat dilihat pada Gambar 3. 


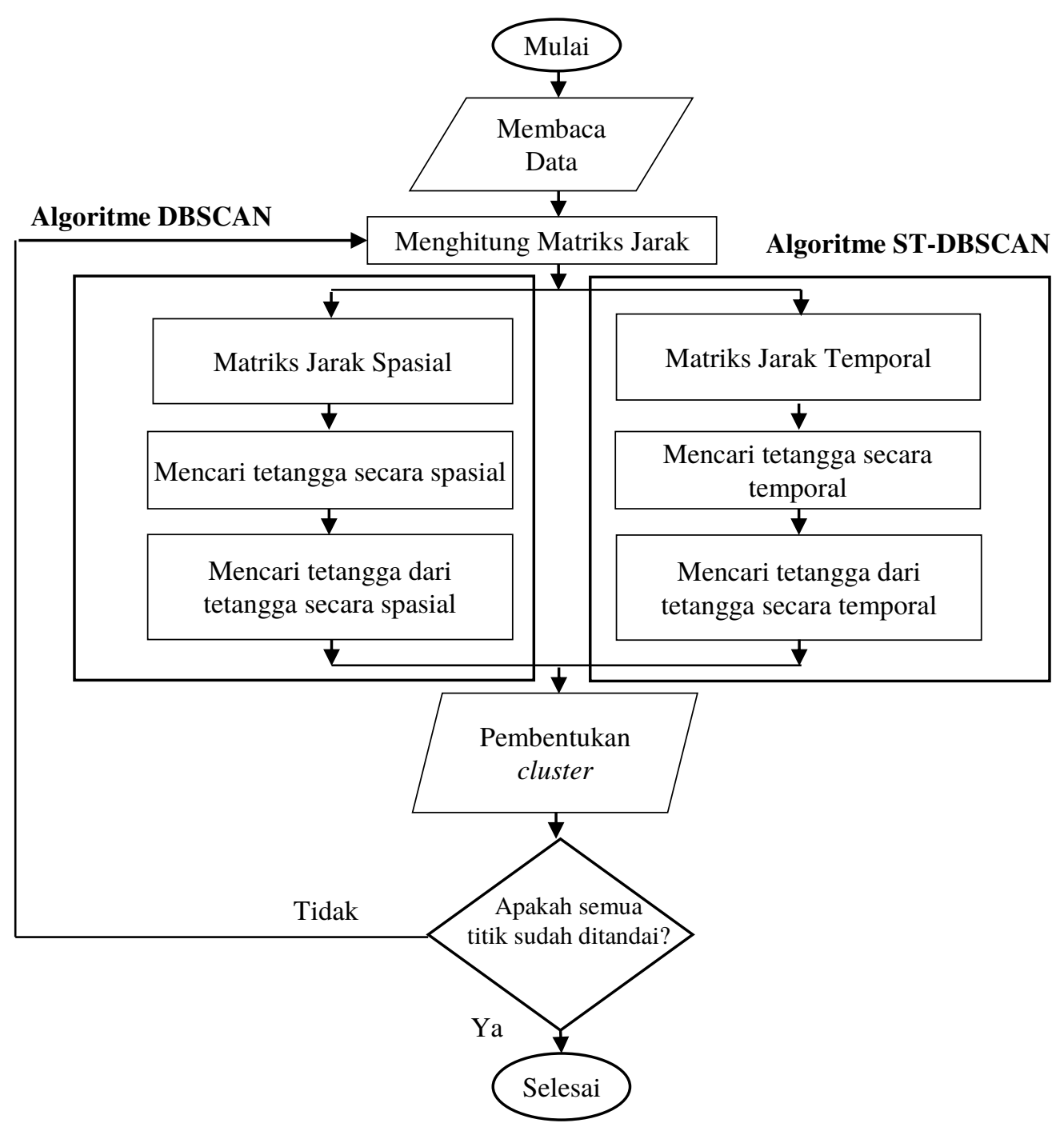

Gambar 3 Diagram alir algoritme

\section{Analisis Cluster}

Pada tahapan ini akan dianalisis apakah cluster tersebut memiliki pola stasionary, reappearing (regular dan irregular), occasional, ataukah track (Pöelitz \& Andrienko, 2010).

\section{Lingkupan Pengembangan}

Pembuatan model clustering dengan menggunakan algoritme ST-DBSCAN ini menggunakan beberapa perangkat keras dan perangkat lunak dengan spesifikasi sebagai berikut:

Perangkat Keras

Processor: Intel(R) Core(TM) i3 CPU M 2330 @ 2.2GHz

Memory: Sodim DDR3 2 GB RAM

Monitor

Perangkat Lunak

Sistem operasi Windows 7 Enterprise 64-bit

Bahasa Pemrograman R-3.0.2 version of R64

Microsoft Excel 2013

Notepad++ 


\section{HASIL DAN PEMBAHASAN}

\section{Praproses Data}

\section{Perubahan format pada kolom date}

Data tanggal akan di ubah ke dalam format number menggunakan Microsoft Excel dimana hari pertama dimulai dari 1 Januari 1900. Pengubahan format ini dilakukan agar ketika terjadi penambahan data sebelum tanggal pertama data yang digunakan saat ini tidak menyebabkan variabel tanggal bernilai -1 jika penanggalan dimulai dari 1 Januari 2008.

\begin{tabular}{|c|c|}
\hline $\begin{array}{c}\text { Tanggal } \\
(\mathrm{mm} / \mathrm{dd} / \text { yyyy })\end{array}$ & $\begin{array}{c}\text { Tanggal } \\
\text { (number) }\end{array}$ \\
\hline $11 / 05 / 2002$ & 37387 \\
\hline $\begin{array}{l}22 / 05 / 2002 \\
29 / 05 / 2002\end{array}$ & $\begin{array}{l}37398 \\
37405\end{array}$ \\
\hline 03/06/2002 & 37410 \\
\hline
\end{tabular}

\section{Reduksi data}

Penelitian ini hanya memerlukan aspek spasial dan aspek temporal untuk proses mining sehingga reduksi data dilakukan dengan memilih 3 atribut dari 11 atribut. Atribut yang terdapat dalam dataset yaitu: longitude, latitude, acq_date, acq_time, brightness, confidence, satelite, bright_t31, frp, scan dan track. Atribut yang dipilih yaitu longitude, latitude yang merupakan aspek spasial dan tanggal pemantauan hotspot sebagai aspek temporalnya.

\section{Perhitungan nilai parameter}

Pada penelitian Purwanto (2012) penentuan nilai Eps ${ }_{1}$ dan MinPts dilakukan dengan perhitungan $k$-dist dengan nilai $\mathrm{k}$ yang bervariasi. Penggerombolan dapat diidentifikasi jika $\mathrm{k}$ tetangga terdekat memiliki jarak yang sama dengan titik yang lain atau dapat dikatakan bahwa titik dalam suatu penggerombolan secara kasar memiliki jarak yang sama.

Optimalisasi nilai $\mathrm{Eps}_{1}$ dan MinPts (k) dilakukan dengan cara melakukan pergeseran nilai Eps $_{1}$ (Gambar 5). Pergeseran nilai Eps 1 dilakukan pada nilai $k=4, k=7, k=15$ dan $k=18$ dengan nilai Eps ${ }_{1} 0.125$ sampai 0.2. Dari pergeseran nilai Eps ${ }_{1}$ didapatkan nilai Eps $_{1}=0.2$ dengan total hasil cluster paling sedikit sehingga pada penelitian ini digunakan Eps ${ }_{1}=0.2$ yang mewakili jarak sekitar $22 \mathrm{~km}$.

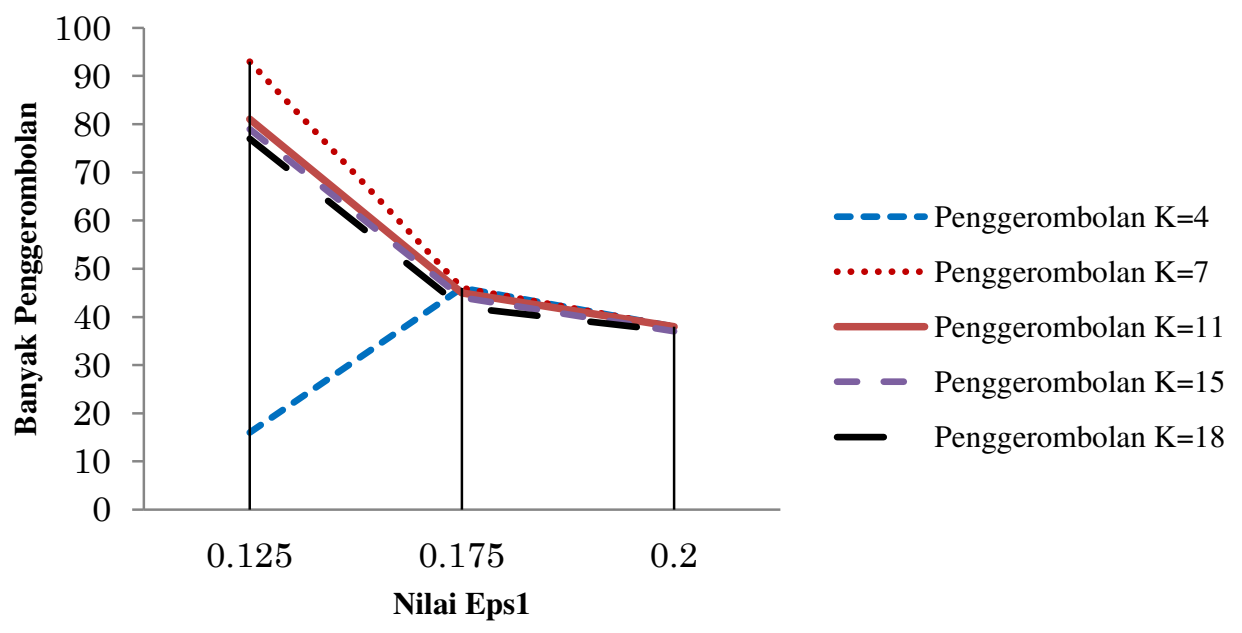

Gambar 4 Grafik pergeseran penggerombolan (Purwanto 2012) 
Gambar 6 menunjukkan jumlah titik yang tidak terdapat di cluster manapun (noise) pada $\mathrm{k}=7$ lebih stabil seiring penambahan nilai Eps ${ }_{1}$. Berdasarkan nilai Eps ${ }_{1}=0.2$ diperoleh $\mathrm{k}=$ $4, \mathrm{k}=7$ dan $\mathrm{k}=11$ memiliki noise paling sedikit sehingga pada penelitian ini digunakan minpts $=7$ dan $\operatorname{Eps}_{1}=0.2$.

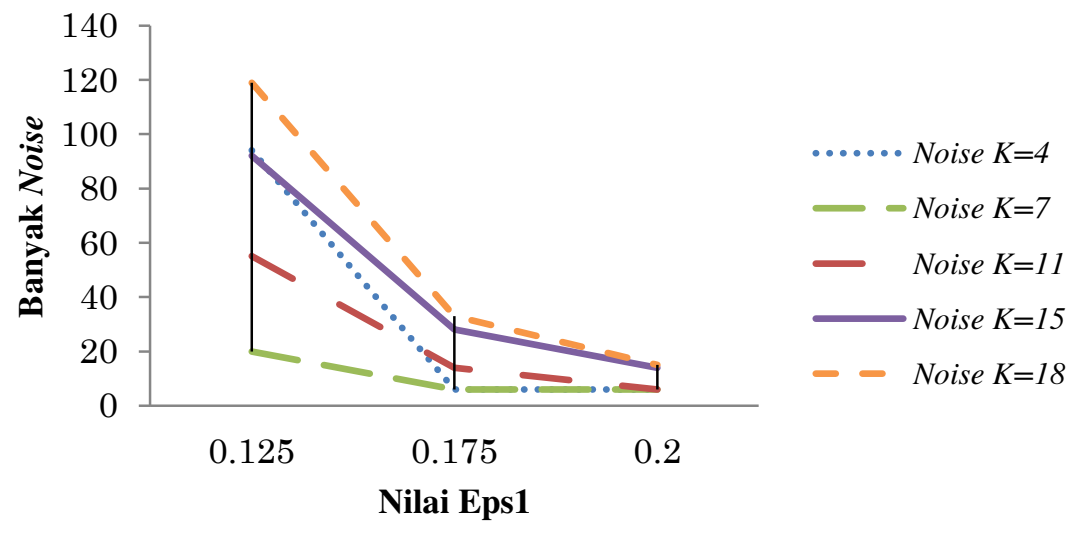

Gambar 5 Hubungan titik noise dengan Eps 1 (Purwanto, 2012)

Pada ST-DBSCAN selain parameter Eps 1 dan MinPts juga digunakan parameter $\mathrm{Eps}_{2}$. Pada penelitian ini nilai Eps 2 yang dipakai adalah 7 meskipun Purwanto (2012) menggunakan nilai 30 sebagai Eps . $_{2} \mathrm{Ess}_{2}=7$ bertujuan agar perubahan cuaca yang terjadi tidak jauh berbeda dan untuk mendapatkan pola dalam rentang waktu yang cenderung lebih kecil.

\section{Implementasi Algoritme ST-DBSCAN Menggunakan R}

Tahap ini dilakukan dengan mengimplementasikan algoritme ST-DBSCAN ke dalam bahasa pemrograman R (Brian \& Kut, 2007). Algoritme dimulai dengan perhitungan matriks jarak euclidean pada aspek spasial dan aspek temporal menggunakan fungsi dist. Fungsi cbind digunakan untuk menggabungkan kolom longitude dan kolom latitude menjadi sebuah matriks. Setelah itu mengubah tipe data "data_spasial dan data_temporal" menjadi matriks karena hasil dist berupa matriks segitiga atas sehingga perlu di normalisasi. Selanjutnya $n$ (row) digunakan untuk menghitung banyaknya baris yang terdapat pada data. Clustering dimulai dari objek pertama $\left(\mathrm{o}_{1}\right)$ di vektor $\mathrm{cv}$. Objek $\mathrm{o}_{2}$ di $\mathrm{D}$ dipilih setelah objek $\mathrm{o}_{1}$ diproses. Jika objek $\mathrm{o}_{1}$ belum termasuk ke dalam cluster, maka dicari irisan dari tetangga $\left(\mathrm{o}_{\mathrm{i}}, \mathrm{Eps}_{1}\right)$ dan tetangga $\left(\mathrm{o}_{\mathrm{i}}, \mathrm{Eps}_{2}\right)$ menggunakan fungsi intersect yang kemudian hasil irisannya dimasukkan ke dalam variabel reachables. Suatu objek dikatakan noise jika jumlah objek yang dikembalikan dalam Eps-Neighborhood kurang dari MinPts, dalam hal ini berarti $\mathrm{o}_{\mathrm{i}}$ tidak memliki cukup tetangga untuk membentuk sebuah cluster. Eps-Neighborhood adalah objek yang terjangkau secara spasial dan temporal oleh objek ke-i. Objek dengan label noise dapat berubah pada proses selanjutnya jika objek tidak directly density-reachable namun densityreachable dari objek-objek lain di D. Directly density-reachable merupakan objek yang terjangkau langsung oleh objek ke-i sedangkan density-reachable adalah objek yang terjangkau oleh tetangga dari objek ke-i (Gambar 7).

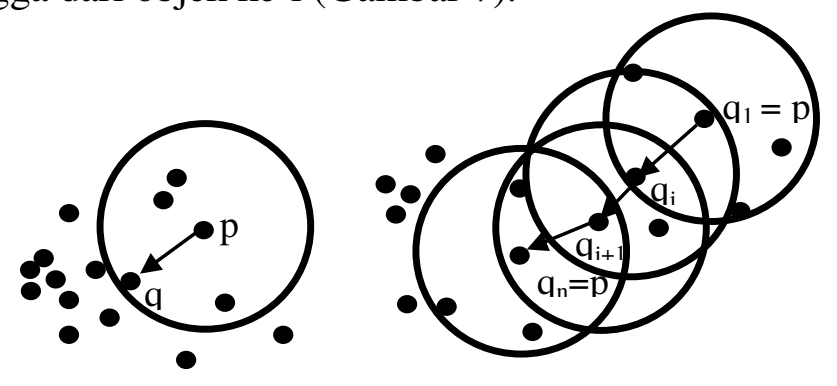

Gambar 6 Directly density-reachable dan Density-reachable 
Implementasi algoritme dilakukan dengan memodifikasi fungsi dbscan yang terdapat pada package fpc. Potongan program modifikasi dbscan dapat pada Gambar 8.

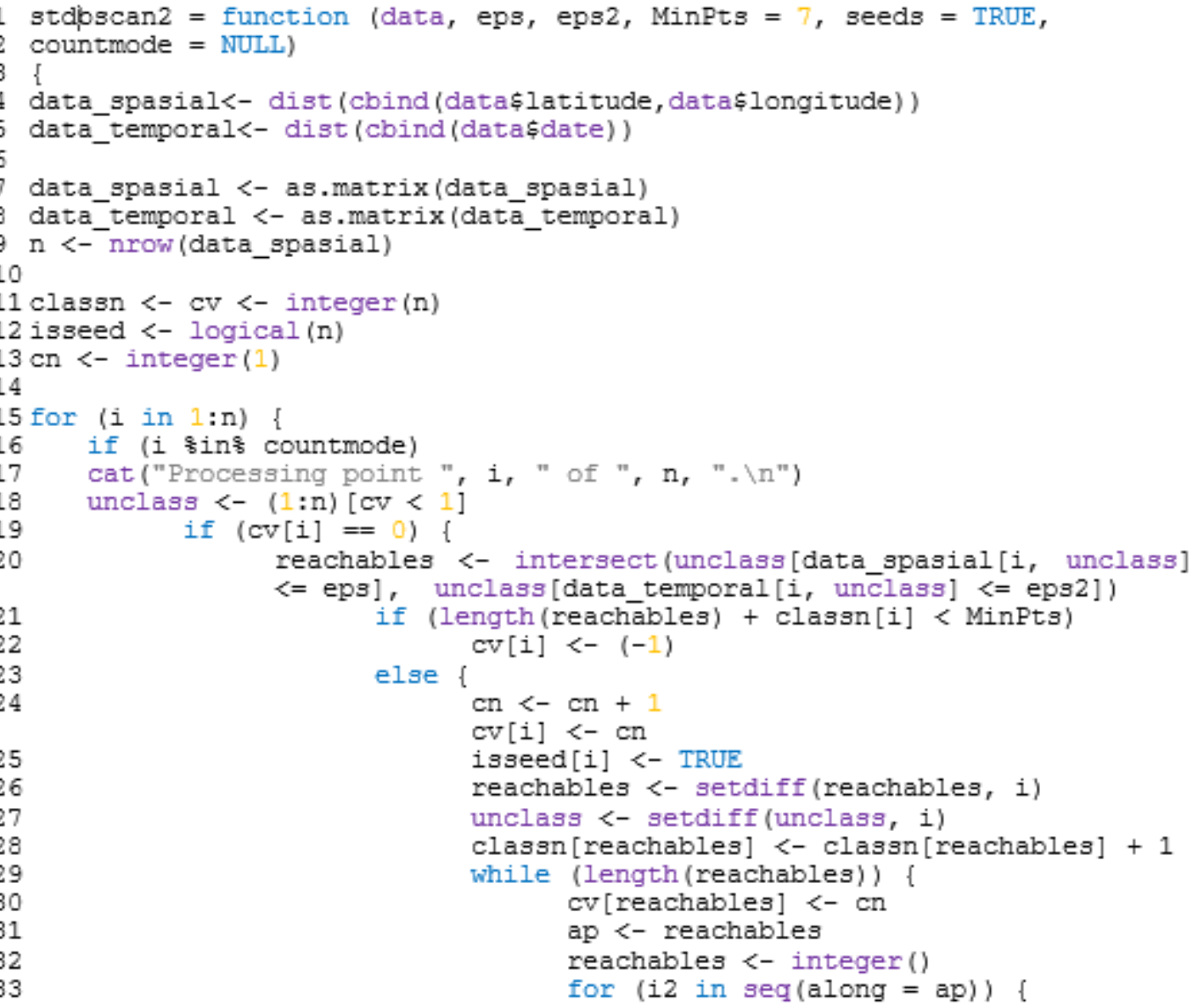

Gambar 7 Kode Fragment dbscan

\section{Clustering Menggunakan ST-DBSCAN}

Proses clustering berhasil dijalankan dengan nilai tiap parameter yaitu, $\operatorname{Eps}_{1}=0.2$, Eps $_{2}=7$ dan MinPts=7 serta menghasilkan 41 cluster dengan 712 noise . Cluster ini kemudian dibagi menjadi cluster yang bisa dianalisis dengan cluster yang tidak bisa dianalisis. Gambar 8 menunjukkan banyaknya titik per cluster dimana garis abline vertikal merupakan garis perpotongan antar cluster yang bisa dianalisis dengan yang tidak. Cluster yang dapat dianalisis merupakan cluster yang setidaknya memiliki minimum 30 hotspot, hal ini dikarenakan pola cluster sudah dapat dikategorikan tipe polanya menurut Pöelitz dan Andrienko (2010) sedangkan cluster yang memiliki jumlah hotspot kurang dari 30, pola cluster dari cluster tersebut tidak dapat terdeteksi. Cluster yang memiliki jumlah hotspot minimum 30 hotspot dapat dikatakan sebagai cluster besar. 


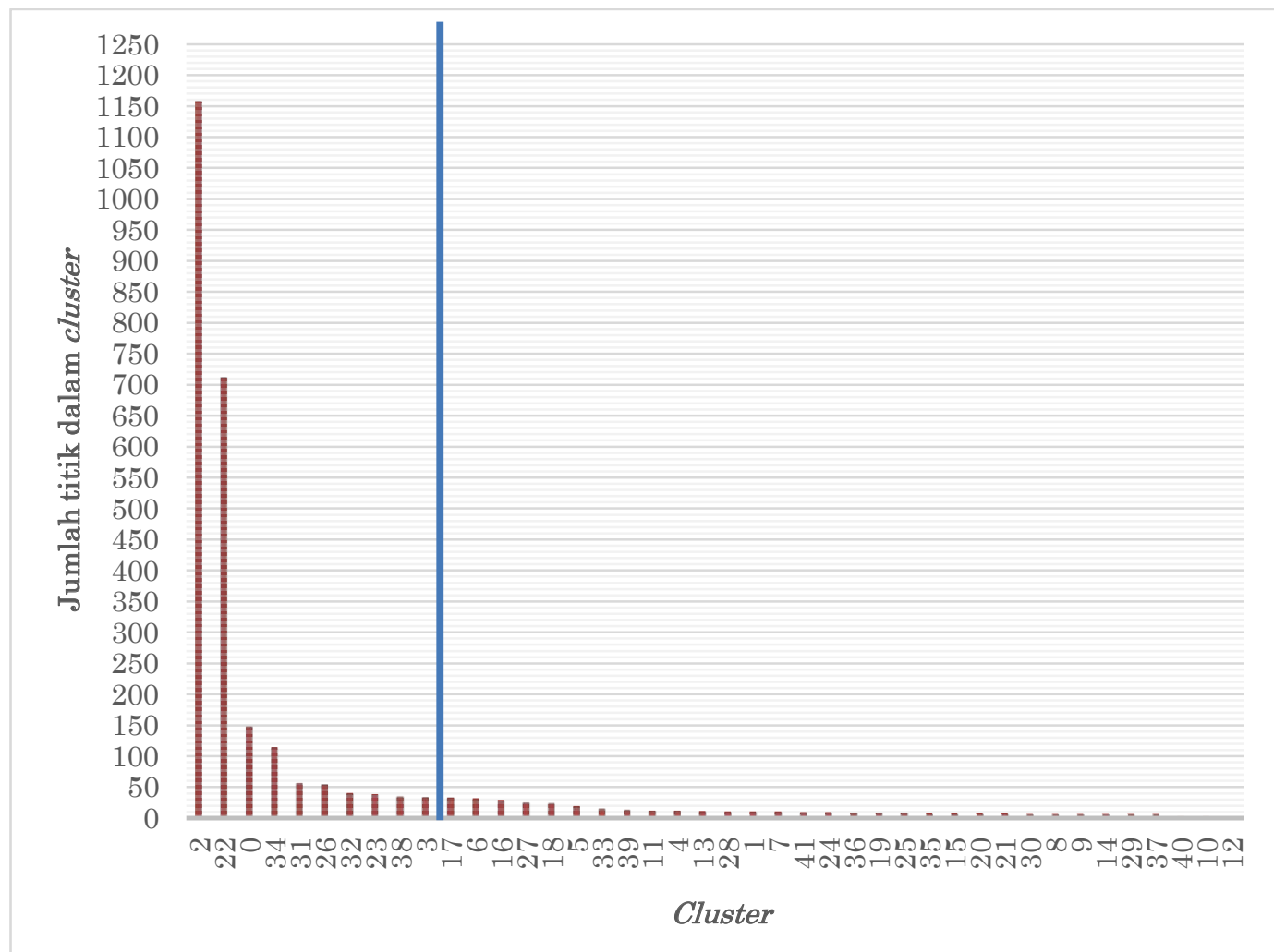

Gambar 8 Jumlah titik per cluster

\section{Analisis Cluster}

Implementasi algoritme ST-DBSCAN dengan menggunakan bahasa pemrograman $\mathrm{R}$ yang diaplikasikan pada dataset hostspot di Sumatera Selatan dilakukan untuk menemukan pola kebakaran hutan. Pada hasil cluster didapatkan 13 cluster yang termasuk ke dalam cluster besar yang dapat dianalisis polanya. Tabel 2 menunjukkan cluster-cluster yang masuk ke dalam cluster besar.

Tabel 4 Jumlah hotspot dalam cluster besar

\begin{tabular}{cc}
\hline Cluster ke- & Jumlah Hotspot \\
\hline 2 & 2029 \\
22 & 1157 \\
34 & 150 \\
31 & 115 \\
26 & 58 \\
32 & 55 \\
23 & 41 \\
38 & 39 \\
3 & 36 \\
17 & 35 \\
6 & 34 \\
16 & 30 \\
\hline
\end{tabular}

Cluster besar kemudian dianalisis polanya berdasarkan tipe pola data spatio-temporal menurut Pöelitz dan Andrienko (2010). Ilustrasi pola dapat dilihat pada Gambar 9. 
$\mathrm{t}=$ periode waktu
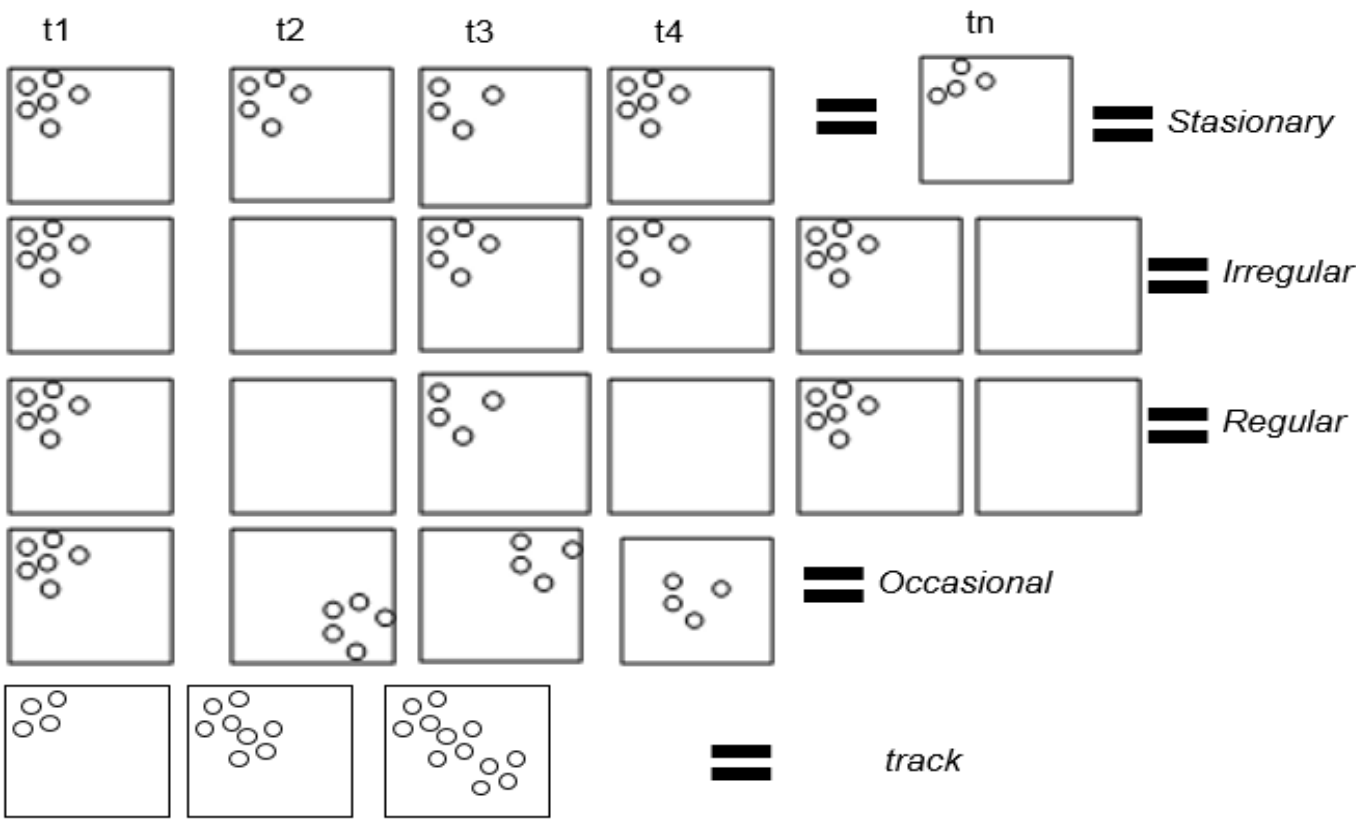

Gambar 9 Ilustrasi pola spatio-temporal (Purwanto 2012)

Tiap cluster besar akan dibagi menjadi per periode, yaitu tujuh hari untuk perbandingan lokasi persebaran hotspot pada suatu periode dengan periode selanjutnya. Waktu 7 hari dipilih karena kondisi cuaca yang hampir mirip dan perubahan cuaca yang tidak signifikan. Sebagai contoh pada cluster 2 didapatkan 16 periode (Gambar 10).

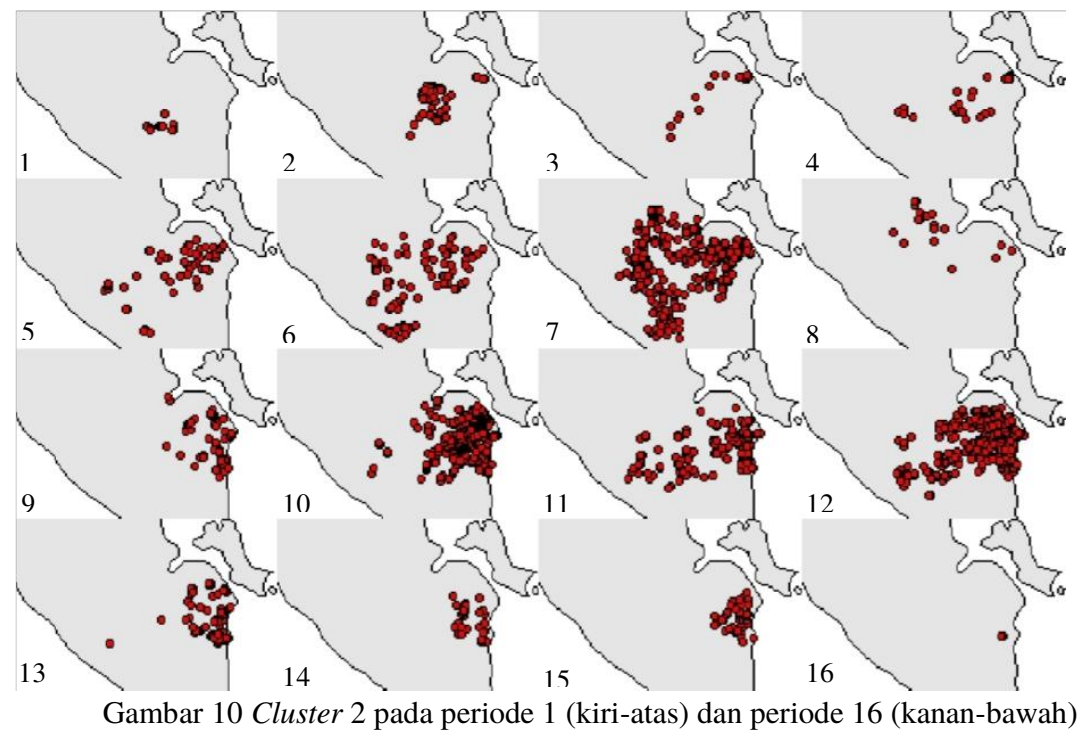

Pada periode 7 hotspot muncul pada seluruh kabupaten kecuali kota. Selanjutnya pada periode 10 dan 12 hotspot terpusat pada Kabupaten Ogan Komering Ilir maka dapat dikatakan cluster 2 mempunyai pola occasional.Analisis 13 cluster besar pada penelitian ini menunjukkan bahwa tipe pola spatio-temporal yang paling banyak muncul adalah pola stationary. Terdapat 7 pola stationary yang muncul dan 4 diantaranya terdapat di kabupaten Muara Banyu Asin. Dengan adanya hasil analisis berupa pola kebakaran hutan diharapkan pemerintah dapat mengambil tindakan yang tepat untuk menangani kejadian kebakaran hutan. Sebagai contoh, untuk pola stationary maka dapat dilakukan pemberitahuan terhadap masyarakat sekitar dan pihak terkait untuk lebih waspada terhadap kemunculan kebakaran hutan agar dapat meminimalisir dampak yang terjadi. 


\section{SIMPULAN}

Bahasa pemrograman $\mathrm{R}$ mampu mengimplementasikan algoritme ST-DBSCAN. Dengan mengimplementasikan algoritme ST-DBSCAN menggunakan $\mathrm{R}$ runtime yang didapatkan adalah 1.14 detik. Pada dataset Sumatera Selatan ditemukan 41 cluster dengan 13 cluster besar yang dapat dianalisis. Tipe pola spatio-temporal paling banyak ditemukan adalah tipe pola stationary yang banyak muncul di Kabupaten Musi Banyu Asin.

\section{DAFTAR PUSTAKA}

Adinugroho WC, Suryadiputra INN, Saharjo BH, Siboro L. 2005. Panduan Pengendalian Kebakaran Hutan dan Lahan Gambut. Proyek Climate Change, Forests and Peatlands in Indonesia. Bogor: Wetlands International-Indonesia Programme dan Wildlife Habitat Canada.

Birant D, Kut A .2007. ST-DBSCAN: An Algorithm for Clustering Spatial-temporal data. Data and Knowledge Engineering. 60:208-221.

Gaonkar M N, Sawant K. 2013. AutoEPsDBSCAN : DBSCAN with Eps Automatic for Large Datase. 2:2319-2526.

Pöelitz C dan Andrienko N. 2010. Finding Arbitrary Shaped Cluster with Related Extents in Space and Time. IEEE-VGTC Simposium on Visualization.

Purwanto U Y, Barus B, dan Adrianto H A. 2012. Spatial clustering of hotspot using DBSCAN and ST-DBSCAN. Bogor (ID): Institut Pertanian Bogor.

Rao K V, Govardhan A, dan Rao K V C. 2012. Spatiotemporal Data Mining: Issues, Tasks and Applications. Chennai (IN): Engg Journals Publications.

Shekhar dan Chawla. 2003. Spatial Databases A Tour. New Jersey. Prentice Hall 